\title{
Adherence in patients with atrial fibrillation treated with dabigatran
}

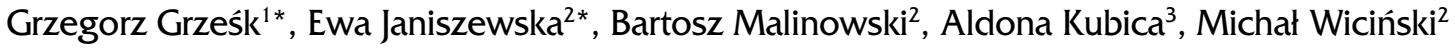 \\ $12^{\text {nd }}$ Department of Cardiology, Division of Clinical Pharmacology, Faculty of Health Sciences, Ludwik Rydygier Collegium Medicum \\ in Bydgoszcz, Nicolaus Copernicus University, Torun, Poland \\ 2Department of Pharmacology and Therapeutics, Ludwik Rydygier Collegium Medicum in Bydgoszcz, Nicolaus Copernicus University, \\ Torun, Poland \\ ${ }^{3}$ Department of Health Promotion, Ludwik Rydygier Collegium Medicum in Bydgoszcz, Nicolaus Copernicus University, Torun, Poland \\ *Both authors equally contributed to the study.
}

\section{INTRODUCTION}

According to the 2003 definition proposed by the World Health Organization, adherence is the degree to which a patient's behaviour follows the medical recommendation obtained from a healthcare professional. This is an active process wherein the patient is a partner in the development of a therapy plan [1]. Failure to follow the physician's instructions is a serious threat to the patient's health as well as a source of increased healthcare costs. It is particularly difficult to maintain adherence in chronic and asymptomatic diseases [2-4].

The measurement of the drug's blood concentration is the most reliable way to verify the patient's self-report on adherence. However, in the case of non-vitamin K antagonist oral anticoagulants (NOACs), it is an expensive method and is available only in a few medical research centres in Poland. There is also the risk of inaccurate evaluation of adherence due to individual variations in metabolism rates and possible drug interactions that influence plasma drug concentrations $[3,5]$.

Atrial fibrillation (AF) is one of the most common heart arrhythmias. It increases the risk of death due to cardiovascular causes and of other events, predominantly stroke. The first-choice drugs for the prevention of thromboembolic events are NOACs, including dabigatran [6]. Therefore, adherence to treatment with NOACs is becoming a particularly important issue, given the lack of an objective and easily accessible verification method in clinical practice.

\section{METHODS}

Forty consecutive patients with $\mathrm{AF}$ treated with dabigatran were enrolled in the study. Samples to determine concentrations of dabigatran were taken from 2 to $12 \mathrm{~h}$ after last dose. Plasma concentrations of dabigatran were determined in the Division of Clinical Pharmacology of Ludwik Rydygier Collegium Medicum in Bydgoszcz, Nicolaus Copernicus University in Torun, Poland, by plasma-diluted thrombin time, using the Hemoclot thrombin inhibitor assay (Hyphen BioMed, Neuville-Sur-Oise, France). Descriptive statistics were performed using STATISTICA (StatSoft Inc., 2014).

\section{RESULTS AND DISCUSSION}

All patients enrolled in the study reported taking dabigatran at a dose of $2 \times 110 \mathrm{mg}(\mathrm{n}=13)$ or $2 \times 150 \mathrm{mg}(\mathrm{n}=27)$. The mean age of patients was $70.45 \pm 13.28$ years, $72.5 \%$ of the patients were men, and $67.5 \%$ of the study population were admitted to hospital as planned. The mean $\mathrm{CHA}_{2} \mathrm{DS}_{2} \mathrm{VASC}$ score was $3.95 \pm 1.78$, and the HAS-BLED score, $2.28 \pm 1.13$. The mean estimated glomerular filtration rate, calculated according to the Modification of Diet in Renal Disease formula, was $71.63 \pm 21.99 \mathrm{~mL} / \mathrm{min} / 1.73 \mathrm{~m}^{2}$. The dabigatran concentration in the study group ranged from $0 \mathrm{ng} / \mathrm{mL}$ to $481.78 \mathrm{ng} / \mathrm{mL}$ (median: $119.86 \mathrm{ng} / \mathrm{mL}$; mean: $131.11 \pm 118.54 \mathrm{ng} / \mathrm{mL}$ ). In $27.5 \%$ of patients plasma dabigatran levels were below the optimal therapeutic concentration $(<40 \mathrm{ng} / \mathrm{mL}$ ). The optimal therapeutic concentration (i.e. $40-200 \mathrm{ng} / \mathrm{mL}$ ) was observed in 50\% of patients. Dabigatran concentrations above this range but not associated with a significant increase in the risk of bleeding complications (i.e. $201-400 \mathrm{ng} / \mathrm{mL}$ ) were noted in $17.5 \%$ of patients. Dabigatran concentrations above $400 \mathrm{ng} / \mathrm{mL}$, which is the level associated with a significant increase in bleeding risk, occurred in 5\% of patients. Patients with plasma dabigatran concentrations lower than $40 \mathrm{ng} / \mathrm{mL}$ were included in the non-adherent group because the only explanation for such low levels is failure to take the drug.

Address for correspondence:

Prof. Grzegorz Grześk, 2 ${ }^{\text {nd }}$ Department of Cardiology, Dr. J. Biziel University Hospital No. 2 in Bydgoszcz, ul. Ujejskiego 75, 85-168 Bydgoszcz, Poland, tel/fax: +4852 36556 53, e-mail: ggrzesk@cm.umk.pl

Received: 4.07.2018 Accepted: 2.08.2018

Available as AoP: 11.09.2018

Kardiologia Polska Copyright (c) Polish Cardiac Society 2018 
Similar results were obtained in several recent studies assessing the level of adherence to NOACs in patients with AF. A retrospective analysis by Xiaoxi et al. [7] included 6461 American citizens with AF treated with warfarin (59.1\%), dabigatran (15.7\%), rivaroxaban (19.1\%), or apixaban (6.0\%). The authors analysed the proportion of days covered (PDC) and classified patients with a PDC of $80 \%$ or higher as adherent. The percentage of adherent patients during the initial six months of follow-up was below $50 \%: 47.5 \%$ for NOACs versus $40.2 \%$ for warfarin $(p<0.001)$.

In a study by Shore et al. [8], including 5376 patients with non-valvular $\mathrm{AF}, 27.8 \%$ of the population were non-adherent in the first year of dabigatran therapy. A similar result was shown in a retrospective study by Borne et al. [9], including 2882 patients with non-valvular AF and a $\mathrm{CHA}_{2} \mathrm{DS}_{2}$ VASc score of two or more. Those patients were tested for adherence within a year of introducing dabigatran $(72.7 \%)$, rivaroxaban $(19.8 \%)$, or apixaban $(7.5 \%)$. The percentage of non-adherent patients (PDC $<80 \%$ ) was estimated at $27.6 \%$ for the entire group.

A study by Maura et al. [10] included 22,267 French patients with non-valvular AF treated with dabigatran $(11,141$ individuals) or rivaroxaban $(11,126$ individuals). During over a one-year follow-up, the authors estimated the percentage of adherent patients at only $53.3 \%$ for dabigatran and $59.9 \%$ for rivaroxaban.

The reasons for non-adherence in patients with $\mathrm{AF}$ treated with NOACs include, among others, economic considerations and side effects of therapy or fear thereof. Patients may also misunderstand medical recommendations or not be convinced about the necessity of therapy [3, 4].

In the case of NOACs, higher adherence can be expected for rivaroxaban, which is taken once daily, as opposed to dabigatran and apixaban, which are applied every $12 \mathrm{~h}$ similarly to other long-term cardiovascular therapies $[11,12]$.

Andrade et al. [13] assessed the preferences of Canadian doctors $(n=178)$ and patients $(n=266)$ as well as doctor-patient cooperation regarding NOAC treatment. The authors showed better compliance for patients taking once-daily drugs (rivaroxaban and warfarin). Patients taking apixaban and dabigatran, dosed twice a day, missed their doses during the seven preceding days, and on average $30 \%$ of them were taking the wrong doses, for example, once a day [13].

Good patient-doctor communication is the key to improving adherence. It essentially involves a clear explanation of the disease and the need for treatment, as well as learning about the patient's lifestyle, along with his or her physical and financial capabilities and preferences. The decision about anticoagulant therapy should involve the patient, which leads to a better understanding and acceptance of therapy goals $[2,11]$.
Improving adherence to treatment with NOACs will be a great challenge for medical community in the near future because NOACs have become the drugs of choice in thromboembolic prophylaxis in patients with non-valvular AF.

Conflict of interest: Prof. Grzegorz Grześk received honoraria from Boehringer Ingelheim for lectures. The other authors declare no conflicts of interest.

\section{References}

1. Sabaté E. Adherence to long-term therapies: evidence for action. World Health Organization. 2003.

2. Kubica A, Grześk G, Sinkiewicz W, et al. [Compliance, concordance, adherence in a chronic therapy]. Folia Cardiologica Excerpta. 2010; 5(2): 54-57.

3. Jasińska M, Kurczewska U, Orszulak-Michalak D. [The phenomenon of non-adherence in the pharmaceutical care process]. Farm Pol. 2009; 65(11): 765-771.

4. Kubica A, Ratajska A, Sinkiewicz W, et al. [Causes of poor doctor-patient cooperation in chronic therapy]. Folia Cardiologica Excerpta. 2010; 5(2): 78-83.

5. Stolarek W, Kasprzak M, Obońska K, et al. Acetylsalicylic acid resistance risk factors in patients with myocardial infarction. Pharmacol Rep. 2015; 67(5): 952-958, doi: 10.1016/j. pharep.2015.02.006, indexed in Pubmed: 26398390.

6. Kirchhof P, Benussi S, Kotecha D, et al. ESC Scientific Document Group. 2016 ESC Guidelines for the management of atrial fibrillation developed in collaboration with EACTS. Eur Heart J. 2016; 37(38): 2893-2962, doi: 10.1093/eurheartj/ehw210, indexed in Pubmed: 27567408.

7. Xiaoxi Y, Neena AS, Caleb A, et al. Effect of adherence to oral anticoagulants on risk of stroke and major bleeding among patients with atrial fibrillation. J Am Heart Assoc. 2016; 5(2), doi: 10.1161/JAHA.115.003074, indexed in Pubmed: 26908412.

8. Shore S, Carey EP, Turakhia MP, et al. Adherence to dabigatran therapy and longitudinal patient outcomes: insights from the veterans health administration. Am Heart J. 2014; 167(6): 810-817, doi: 10.1016/j.ahj.2014.03.023, indexed in Pubmed: 24890529.

9. Borne RT, O'Donnell C, Turakhia MP, et al. Adherence and outcomes to direct oral anticoagulants among patients with atrial fibrillation: findings from the veterans health administration. BMC Cardiovasc Disord. 2017; 17(1): 236, doi: 10.1186/s12872017-0671-6, indexed in Pubmed: 28865440.

10. Maura G, Pariente A, Alla F, et al. Adherence with direct oral anticoagulants in nonvalvular atrial fibrillation new users and associated factors: a French nationwide cohort study. Pharmacoepidemiol Drug Saf. 2017; 26(11): 1367-1377, doi: 10.1002/pds.4268, indexed in Pubmed: 28752560.

11. Grześk G, Kubica A, Koziński M, et al. [Drug and pharmaceutical form selection strategy as means of improving the implementation of a therapeutic program]. Folia Cardiol Excerpta. 2010; 5(2): 88-92.

12. Bae JP, Dobesh PP, Klepser DG, et al. Adherence and dosing frequency of common medications for cardiovascular patients. Am J Manag Care. 2012; 18(3): 139-146, indexed in Pubmed: 22435907.

13. Andrade JG, Krahn AD, Skanes AC, et al. Values and preferences of physicians and patients with nonvalvular atrial fibrillation who receive oral anticoagulation therapy for stroke prevention. Can J Cardiol. 2016; 32(6): 747-753, doi: 10.1016/j.cjca.2015.09.023, indexed in Pubmed: 26774235.

Cite this article as: Grześk G, JaniszewskaE, Malinowski B, et al. Adherence in patients with atrial fibrillation treated with dabigatran. Kardiol Pol. 2018; 76(11): 1562-1563, doi: 10.5603/KP.a2018.0194. 